\section{Sylvicultural Research in Bengal}

Most of the provinces in India draw up a quinquennial programme of sylvicultural research work and prepare an annual report on the work undertaken in accordance with the programme. For this purpose a sylvicultural research officer is selected from the ranks of the Forest Department. The annual report on sylvicultural research in the Presidency of Bengal for 1940-41 (Government Press, Darjeeling, 1941) is by Mr. D. A. G. Davidson. In connexion with research in such an important branch of his work as sylviculture, which is its foundation, it appears that at a Divisional Forest Officers' Conference held in Darjeeling in 1940 a resolution was passed which reads, "the practice of allowing divisional officers to undertake research independently of the Sylvicultural Branch should be discontinued and no funds should be provided in future for divisional experiments". It is difficult to understand the meaning of, and the purpose underlying, this attempt at granting a monopoly to a research branch. In forestry, the opportunities for observation by the divisional officer, that is, the man who spends much of his time out in the forests in a definite locality which he can thus get to know with some intimacy-and in India this means large areas-are exceptionally advantageous. The officer may be every bit as observant as the research officer and has better, because more numerous, opportunities for carrying out a piece of research work up to a certain point.

The attempt to introduce exotic, faster-growing species in connexion with forestry has become a common habit in many parts of the world. Experiments in this connexion were commenced at Darjeeling and neighbourhood seventy and more years ago. The research officer is still engaged on these experiments. Attempts have also been made to induce seed production by ringing the trees, after the method practised for fruit trees. But most of the trees ringed in Bengal died. In experimental plots in the Chittagong Hill tracts, although the second story species, Dichopsis polyantha, Artocarpus chaplasha and other evergreen species regenerated profusely, the regeneration of the top species, Garjan (Dipterocarpus), has proved unsuccessful. It may be suggested that the Garjan might be added to the mixture by planting it in lines at 30-40 ft. apart and at such distance in the lines as may be decided, and that big plants should be used. This method has been found successful under somewhat similar conditions in West Africa.

\section{Floatless Pump Control System}

LoNDEx, LTD., 207 Anerley Road, London, S.E.20, have introduced a patented system ("Lectralevel") of floatless liquid level control, designed for automatically pumping out, filling or maintaining the liquid level in a container and employing a single mercury switch for controlling the pump motor starter. The pump suction pipe may be earthed and used as one side of the control circuit, the pressure of which $(25$ v.) is derived from a small double. wound transformer supplied from the power or lighting mains. The control circuit is completed through the liquid to be pumped, and only light insulation is required for the electrodes, which may be of ordinary galvanized wrought iron tubing. A shorter electrode terminating at the highest level of the liquid is connected direct to the relay, and when the level rises to this electrode the relay is energized and the pump motor started. A longer electrode is immersed in the liquid to the lowest required level and is connected to the relay by the same lead through a resistance of a few ohms, its function being to pass sufficient current through the relay to hold the latter closed after the level has fallen below the short electrode. When the liquid level falls beyond the longer (lower) electrode, the relay circuit is interrupted and the pump motor automatically stops. The motor is not restarted until the level reaches the shorter (upper) electrode, when the aforementioned resistance becomes short-circuited and sufficient current flows to actuate the relay. The relay employed is the Londex $L Q A$, the mercury switch of which carries up to $20 \mathrm{amp}$. at $440 \mathrm{v}$. Where the liquid is under pressure or insulated electrodes cannot be employed conveniently, a patented automatic liquid level control device of the induction type is available wherein a float is employed to alter the magnetic conditions in two coils which respectively operate the relays at high- and low. liquid levels.

\section{Medical Services in Argentina}

In a recent paper (Bol. Of. San. Panamer., 21, 955 ; 1942 ) on this subject, Dr. Hugo J. D'Amato, general secretary of the National Department of Hygiene, Buenos Aires, states that malaria exists in endemic form in northern Argentina and sporadically in the coasta] zone. There was a considerable reduction in the number of cases in the endemic area in 1941 when the number of consultations was 193,000 as compared with 231,000 in 1940. More cases of goitre received attention in dispensaries in 1941 than in 1940, there being a high proportion of cases among school-children in the north. The campaign against venereal disease is being actively carried on, as is shown by the fact that the Public Health Department has secured supervision of 717 dispensaries, and serological analysis was being carried out in six cities in 1941. The law for prematrimonial examination is rigorously enforced with excellent results. During 1941, 389 new cases of leprosy were reported, making a total of 4,727 , of whom 46 died. In November a colony of 700 beds was added to the existing four institutions under the supervision of the Public Health Department. The number of plague cases (52) in 1941 was a quarter of that for 1940. The following new health agencies have recently been established: a department of specific prophylaxis against diphtheria ; a national committee of tuberculosis; a department of hydatidosis, and departments of plague and cancer control. Lastly, strict supervision of drugs has been established.

\section{Public Health in Chile}

No epidemics have occurred in Chile since 1939 apart from some cases of typhus which were immediately controlled (J. Amer. Med. Assoc., October 17). Good results have followed the control of malaria in the northern parts of the country. Although the mortality in early childhood is exceedingly high, much attention has lately been given to the feeding of mothers and infants, whose condition, it is expected, will soon improve. According to a new plan, 3,600 persons will have the right to ask for medical care under insurance as well as 200,000 or more children. Since 1940 the health of the people has been improved by providing rations in public restaurants to poor families free of charge. 